\title{
PERFORMATIVE TROLLING: SZUBANSKI, GILLARD, DAWSON AND THE NATURE OF THE UTTERANCE
}

\author{
Belinda MorRissey AND SUsAn YelL
}

\begin{abstract}
In 2012 the Australian public witnessed three important examples of trolling play out in the public sphere that are the focus of this paper: the trolling of Julia Gillard's Facebook page when she attempted to discuss education policy, the anonymous trolling of Charlotte Dawson's Twitter page, and the trolling of Magda Szubanski on YouTube after she came out on The Project. These attacks may seem similar in that a public persona has been ridiculed and denigrated in flamboyant onslaughts. However, we will argue that there are important differences in the effects of these attacks, and that underpinning these are differences relating to the individual persona, the social medium and the nature of the utterance. The attacks on Gillard and Szubanski are primarily descriptive attacks on a deliberate and somewhat stage-managed public performance of identity, not a call to action. On the other hand, the anonymous trolling of Charlotte Dawson, which led directly to her attempted suicide, is clearly a performative utterance from the start, meant to have consequences on the object of attack. In Dawson's case, the separation between her public persona and her private self is far less distinct than in the case of Gillard or Szubanski. These instances demonstrate that trolling exists on a performative continuum, engaging in constant disruption, but also lending itself to the production of social action. The kind of impact trolling will have depends, thus, on the affordances of social media, the persona under attack, and on the very nature of the utterance itself.
\end{abstract}

\section{KEY WORDS}

Troll; Public Debate; Celebrities

\section{INTRODUCTION}

In 2012, in Australia, one of our most successful comedians was denigrated as a 'bush pig' merely for coming out as a lesbian; a host on a popular reality show was encouraged to 'kill herself'; and the then Prime Minister was ordered to cook dinner for one of her constituents and asked about the colour of her pubic hair. Such is the nature of unpoliced public debate. In all three cases, the social media sites of each of these women provided those with a sexist and homophobic agenda an extraordinary lien to literally write whatever they wished. This was accommodated through the phenomenon of trolling, which, while not especially new, certainly took on a new vigour at this time. Although public figures have always been at the mercy of debate and abuse, the public is generally well aware of the risk of legal action to punish specific 
slander or vitriolic insult uttered in conventional media. Not so with the Internet, where trolls seem to believe that they are able to write whatever they please, with few, if any, consequences to themselves. ${ }^{1}$

This paper will discuss three cases where the level of trolling was both unprecedented and especially vicious. They include the trolling of Madga Szubanski on YouTube after she came out on The Project; the trolling of Julia Gillard's Facebook page when she attempted to hold a forum on education policy; and finally, the trolling of the Twitter account of Australia's Next Top Model host, Charlotte Dawson, after she attempted to gain justice over a specific instance of malice. In Szubanski's case, the trolls' comments, while evidently hurtful, seem almost generic to the occasion: a woman comes out as a lesbian and is immediately denigrated for her looks. The Gillard trolling contains many features of relatively generic attack as well: she is taunted with insults which have been used against powerful women for decades in being told to 'get back to the kitchen' and that her voice shrieks like 'nails on a blackboard'. Far worse, in her case, were comments relating to her recently deceased father, in clear reference to Alan Jones' statement that her father would have 'died of shame' at his daughter's 'lies' (Hall). The Dawson example is, by far, the most extreme. In this instance, this 'mean' reality TV judge was told to 'please go hang yourself', to 'stick her head in the toaster' and sent images of bloodied corpses after she defended one of her supporters from a nasty attack regarding the woman's deceased husband who had killed himself (Hornery and Hall, Baird). This assault had the most severe consequences as Dawson was hospitalized for attempted suicide and sadly, she subsequently succeeded in committing suicide in 2014.

At first glance, all three cases may seem similar in that a public persona was attacked and denigrated in a flamboyant manner using the remarkable capacity of social media to do so. In this paper we argue that there are important differences in the effects of these attacks, relating to the performative and affective nature of the utterances in each case, the persona and the social media platform.

J.L. Austin's theory of the utterance posits a basic difference between illocutionary (or descriptive) speech acts, and perlocutionary speech acts which function as a call to action. Using this, admittedly controversial, distinction, it is relatively easy to argue that the trolling of Szubanski and Gillard, while cruel, is nevertheless illocutionary. The trolling of Dawson, on the other hand, is a clear example of the perlocutionary utterance, designed to have direct consequences for the object of attack.

The instances that we discuss in this paper demonstrate that trolling exists on a performative continuum, from disruption to the production of social action. Trolling can be described as the Internet's signature mode of discursive politics, at once disruptive for the sake of an anarchistic vision of political life, while using the freedom of the Internet to insert wellplaced and necessary commentary in an idealistic vision of true democracy. Our examples show that trolling can be both repetitively banal and tremendously effective, both utterly pointless and utterly shameful. We assert that the kind of impact trolling will have depends on its discursive context and on the very nature of the utterance itself. The force of the speech act is, thus, bound up with its affective intensity.

Trolling has been defined in a variety of ways. For a number of writers, trolling is considered to be a time-wasting activity, where a participant deceitfully posing as genuine draws others into pointless and circular discussions (Donath, Dahlberg, Herring et al, Turner et al). This relatively benign version of trolling takes its cue from a fishing term, where a baited line is dragged behind a boat (Oxford English Dictionary), but could also be connected with the Scandinavian hairy monster hiding beneath a bridge hoping to snare hapless strangers (Herring 
et al 372). This latter example leads to far more malevolent conceptions of trolling behaviour. Trolling has sometimes been contrasted with 'flaming', defined as insulting, provoking or rebuking messages sent specifically to vulnerable or naïve participants (Herring et al 372). However, the two frequently merge, as, in more recent years, trolling has become a catch-all term for a suite of negative behaviours (Hardaker 224).

Rebecca Rafferty notes in her 2011 study that trolls who are deliberately insulting tend to be motivated by three reasons: informal social control, dominance and entertainment. Informal social control is usually carried out by people known to the victim and it is effectively a form of 'cyber sanctioning' for perceived bad behaviour (27). Dominance, on the other hand, is defined as 'the attempt to hurt, humiliate, or influence the behaviour of another individual in order to gain or regain access to some valued resource' (Rafferty 33), and is generally carried out by former partners in romantic relationships who are anxious to either regain control over the partner, or to make them miserable. The most important of the three motivations for our purposes in this paper is the entertainment motivation. In Rafferty's study, entertainment was given as the most popular reason for cyber bullying or online aggression (37). The desire is to annoy or to provoke the victim into exhibiting anger or misery through persisting with harassment long after being asked to stop (37). Anonymity is vitally important to this sort of trolling as it allows perpetrators a sense of power over their victim, and a feeling of invulnerability from any form of consequences to themselves (38). Such trolling is considered 'successful' when the victim finally responds in the way suggested, or when others applaud the troll's posts (Hardaker 233).

It would seem then that trolling, at least of the malicious sort, is conducted by people who 'take pleasure in disrupting the social order out of anger, perversity or contempt' (Herring et al 382). While trolls interviewed in Jenny Brockie's Insight programme claimed their trolling was motivated by the desire to create comic effect and to expose hypocrisy, illogical argument or fallacious reasoning, or as a form of ideological resistance, one might argue that malicious trolling, whether banal or incisive, would rarely be motivated by anything other than very personal peeves. The relation between the public persona of the troll as manifested in their online discourse, and their private selves is complex and apparently contradictory. As Elizabeth Grice notes in relation to the case of troll Brenda Leyland, who committed suicide after being exposed for her relentless online abuse of Kate and Gerry McCann, "the image of the incoherent, half literate troller who spits poison as a reflex compensation for lack of self-esteem" is far from the truth (22).

The notion of 'persona' is valuable here in distinguishing the effects (and affects) experienced by public identities under attack in instances of trolling. The concept of persona as we are using it here is based on the poststructuralist argument that identities are not psychologically stable entities but are produced through acts of discourse. Identity is "not a fixed property of individuals but ... part of an ongoing process by which subjects are constituted" (van Zoonen 123). The production of any persona is then an ongoing performance, which is open to contestation. As Judith Butler has observed, such a production is the "reiterative and citational practice by which discourse produces the effects that it names" (2). Thus, persona is a fundamentally performative and denaturalised concept referring not to an autonomous and stable identity, but to an array of constructions. Public figures such as Gillard, Dawson and Szubanski operate with one or more public persona, in addition to their private 'selves', and use social media in a more or less 'managed' way to perform these personas. Marshall and Barbour argue (following Jung) that persona is: 
a strategic public identity, not necessarily in tension with an inner soul of self and individual ... but a way to manage the various dimensions of life and its public formation of the self. Persona can be seen as something that needs to be managed and ... a personal practice that is performed in order to enter the social world in some particular way (4).

For celebrities and other public figures who are required to negotiate the relation between the public and private personae on a daily basis, there are significant risks if the boundary is unstable or the distinction unclear. The consequences of a close versus distant relation between their public and private persona can be profound, as these case studies will demonstrate. ${ }^{2}$

We argue that we can learn a great deal about the nature and power of trolling and its effects by using theories of the utterance - specifically speech act theory and implicature theory. J.L Austin first introduced the distinction between utterances whose pragmatic function is to describe a state of affairs, which he called constatives (3) and those that perform an action, which he termed performatives (6). That is, to say or write something is not merely to produce a sequence of words with certain meanings, but to perform a kind of act, which may then have particular consequences. Austin (109) further distinguishes the act performed in saying something (its illocutionary force) and the effect or result of the act (its perlocutionary force). In relation to this paper, a troll may attempt to insult someone by calling them a 'slut' and the person may indeed feel hurt or insulted (the perlocutionary act) or may merely laugh off the insult as an obvious attempt to insult or provoke. Perlocutionary force is thus not predictable from nor a direct consequence of the illocutionary act, and also cannot be judged based on the grammatical form of the utterance; it is very much linked to the ripples of affect, as we'll discuss further below.

Numerous types of speech acts can be distinguished and these can be grouped into four basic categories: statements, questions, offers and commands (Halliday 69). These categories are based on the understanding that all utterances are performative in the sense that all utterances, in social contexts of interaction, have illocutionary force. The purely constative act which is a neutral statement of fact not designed to produce any corresponding response from the hearer is a theoretical type which is rare in actual contexts of interaction, including online discourse. Nevertheless, we argue that it is theoretically necessarily and analytically useful to distinguish between speech acts that are primarily descriptive and those which are directed towards inciting action. To understand the grammatical structure and performative nature of trolling, we will consider the illocutionary and perlocutionary forces, not only of 'obvious' performatives (commands, offers, threats, and so on) but also various types of statements and questions.

Trolls may make statements, ask questions, offer to perform services, or command others to act. In many cases, these trolling utterances can be perceived as speech acts which seem to flout, or perhaps ignore altogether, that which H. Paul Grice described as the cooperative principle in conversation, and in discourse more generally. ${ }^{3}$ Grice's principle asserts that participants in a dialogue will attempt to be as informative, truthful, relevant, clear and unambiguous as they can in order to communicate effectively and to maintain relationships. When these rules of communication are deliberately flouted, participants may deduce alternative meanings since the literal meanings do not appear to comply with the cooperative principle. These implicatures require participants to infer meanings other than those stated. While it may seem that the language used in the three cases we are discussing is characterised by a consistent violation of the cooperative principle, nevertheless these speech acts are clearly meaningful, and so do take on the status of implicatures. For example, several of the utterances, such as when Julia Gillard is told to 'Get my dinner ready', or Charlotte Dawson is instructed to 
'put your head in the toaster', are commands which are clearly not meant to be taken literally, and therefore must be interpreted as insults.

Both are impossible acts: Julia Gillard is being addressed as down-trodden housewife in relation to her interlocutor; Charlotte Dawson would find it impossible to place her head inside a toaster. However, they form part of the conversational pact with the interlocutor that requires an interpretation of their 'relevance'. In both cases, they demand that the reader infer that these women are not worthy of respect: the command to cook is used to denigrate Julia's status as Prime Minister; an act designed to deform her face, and thus her ability to carry on her career, is prescribed for Charlotte.

To better understand the nature of such speech acts, we also need to consider the way illocutionary force is bound up with affect. By affect, we mean the capacity of the body to affect or be affected (Massumi, Parables 15). Following Spinoza, Brian Massumi further describes affect as a 'pre-personal intensity corresponding to the passage from one experiential state of the body to another' (Massumi, 'Autonomy of Affect' 222). We use it here particularly as it relates to changes in emotional states, and include the body's capacity to incite affects through discourse.

While the concept of affect as it has been taken up by cultural studies is usually regarded as outside signification and as non-discursive, Massumi does acknowledge the possibility that affect can be discursively captured (see Gilbert 14). Atkinson and Yell argue that there is a complex relation between affect and discourse - since utterances are enunciative acts which emanate from bodies, even in cyberspace - and these bodies use discourse to react to bodily experience and to transmit and evoke further affective states in themselves and others. Trolling is a discursive act that provokes affects and incites further discourse and sometimes other forms of embodied social action. We argue that the grammar of trolling speech acts cannot be understood without consideration of its capacity to provoke affects. Indeed, this is the driving force underpinning acts of trolling.

In the following we analyse both the types of affects and the types of speech acts performed in these instances of trolling. The grammar of trolling utterances allows affect to be linguistically 'captured' and transmitted or transmuted, with varied illocutionary and sometimes perlocutionary force. Trolls use affective triggers including explicitly emotive terms which present positive or negative evaluations, often of high intensity ('fat', 'ugly', 'disgusting'), as well as using expletives and abusive language or evoking scenarios which invite a strong emotional response. These, when combined with directly performative utterances (e.g. commands like 'kill yourself'), produce powerful affective/perlocutionary force.

These affects are in turn further mitigated or enhanced by the affordances of different social media platforms, such as YouTube, Facebook and Twitter. Twitter is a "microblogging site" with a "directed friendship model" (Marwick and boyd 116) in which participants choose to follow particular Twitter account holders. Facebook is also based on a directed friendship model but its settings can be adapted to enable public or private access to content, and when settings are public anyone can view or comment on the site's content. Facebook sites can be specific to an individual or used by a group or a public figure, enabling strategic presentation of a persona which may be more or less detached from a private self. Both YouTube and Facebook function as repositories or databases for content created by an individual or organization or hosted on behalf of a third party (Paolillo 156). They have the additional feature of allowing posts or comments to be added and to be visible long after the interaction has taken place. In the case of Facebook, this content is usually directly related to the construction of a particular persona, their tastes, interests, relationships and activities. Whereas YouTube, as a video 
hosting site, is the least personal of the three platforms, often parasitic on other media (such as movies, music videos and broadcast television) and not specific to an individual, unlike Twitter and Facebook. All three social media afford public opportunities to participate in extended dialogue (and thus opportunities for trolling) but in the case of Twitter, the short 140 character tweets directly address the Twitter account holder and more closely approximate real-time conversation whereas posts on Facebook and YouTube enable lengthier posts and can be responded to over a period of hours, days or even months, and thus lack the rapid-fire immediacy of Twitter.

\section{Case Study 1: MAgda SzUbanski on YouTube}

When Magda Szubanski publicly 'came out' on TV panel show The Project in February 2012 a clip was immediately posted on YouTube, where it rapidly accumulated a large number of comments, and comments continued to be added over a period of some months. Amongst apparently genuine attempts to debate Australian government policy and cultural attitudes to same-sex marriage, and messages of personal support for Magda's courage in expressing her own sexuality and her support for gay marriage, were inflammatory statements denigrating homosexuals in general (particularly lesbians), and homophobic insults directed at Magda.

The reaction of these YouTube trolls was perhaps unexpected, given Magda's wellknown and well-loved public persona. She is possibly best known for her work on the television series Kath and Kim, where she played the loveable, but gormless, Sharon, forever on the receiving end of Kim's jokes and aspersions. Magda previously had a well-known comic persona in other shows as well, such as Fast Forward and Big Girl's Blouse, where she once again played likeable characters. Her acting career extended to playing Esme Hoggett in the Babe films, which were internationally popular and the science fiction series Farscape. On top of her acting career, Magda was also a spokesperson for Jenny Craig as she publicly battled her weight problems, with the support of the Australian public. In short, Magda had developed a warm, funny, charming public persona by the time she decided to reveal her sexuality. Even when she did, this was not considered much of a 'scoop' in journalistic terms. As the Sydney Morning Herald noted, it was 'one of the entertainment world's worst kept secrets' (Quinn). Yet, the trolls were vitriolic in their abuse, leading to the inescapable conclusion that it wasn't Magda's confession they were concerned with in particular, but instead, the notion of lesbianism in general and the idea of anyone 'coming out' at all.

The trolls were primarily concerned with the existence of any lesbians in their midst, which is evident in their utterances that predominantly took the grammatical form of descriptive third person statements - they were about Magda (or gays/lesbians in general) rather than being addressed directly to her. The only time the second person ('you') was used in a statement was to issue a generalised (future) threat to supporters of homosexuality ('Magda is going to hell and so are all you fag enablers'), albeit one not to be carried out by the speaker but by an unnamed higher power. Some included the use of the first person to project the speaker's opinion ('Wow I'm shocked... NOT', and 'I notice lots of fat cake eaters are carpet munchers'). Such statements violate Grice's principle for the speaker to be truthful (i.e. sincere) and unambiguous, requiring other participants on the YouTube site to read the first example as sarcasm and the second as an insult (and one in which the participant must be complicit in recognising and decoding the metaphor of a 'carpet muncher').

Within the ongoing 'conversation' on this YouTube comments page, these evaluative statements are speech acts which are designed to incite responses - the posters are not making a statement as a disinterested contribution to knowledge, but an affectively loaded expression 
of opinion, designed to incite equally affectively loaded responses. The evaluative terms are strongly negative homophobic terms of abuse ('ugly dyke', 'carpet muncher', 'carpet licker'), insults based on physical appearance ('fat ugly unfuckable pig', 'a whale like her', 'disgusting to look at', 'disgusting overweight bitches') and include generic statements such as 'no man in his right mind would want to fuk [sic] a whale like her'.

These insults are perverse but also predictable and banal. The use of explicit homophobic language is crude, unskillful and reductive, with its references to appearance, body weight and physical attractiveness and the use of animal terms. Magda Szubanski was being informed that her ugliness would preclude heterosexuality - effectively an implicature asking readers to infer boundaries and makes specific that Magda is to be reviled as an outsider. The language expresses primal affects of revulsion, disgust and contempt. While these statements undoubtedly have the potential to hurt and contribute to a discursive universe in which homophobia continues to exist, their reflexive rehearsal of primitive homophobia seems to blunt the affective force of these utterances. One potential reading of these utterances is that the trolls are taking a position just to get a reaction through such 'ludicrous rants' (Narraine 146).

However, the trolls gained little traction or support for their trolling. Some posters responded to the trolls' comments, but if anything, the trolls incited increased positive responses in support of gay marriage and in praise of Magda Szubanski. Furthermore, there is no evidence of any perlocutionary effects on the primary subject of these trolls, Magda herself, who is not a participant in this conversation and apparently unaffected by the existence of these comments. The effects (and affects) of the trolling are mitigated by the affordances of YouTube, in that its primary function is as a video hosting site and it is not personal to an individual. Furthermore, because both the original content (in this case the footage from Magda's appearance on The Project) and the sequence of comments on this, are archived on the site, the debate does not necessarily occur in real time, nor does it necessarily involve the denigrated individual as an interlocutor. Finally, the pace of the debate can be extended over days or months, again diminishing its affective intensity as a concentrated onslaught of comments. In terms of the definition of trolling, this is an example of 'unsuccessful trolling' (for the trolls), and perhaps offers some support for the notion that trolling can indeed make a positive contribution to internet discourse, since in this case it activated others to articulate and defend their views in opposition to discursive positions that were intolerant, unreasonable or inflammatory.

\section{CASE STUdy 2: JULIA GiLlaRD ON FACEBOOK}

In October 2012 then Australian Prime Minister Julia Gillard engaged in what was touted as a 'first for a federal politician' (Hall), conducting a live chat session on Facebook with the aim of discussing education policy and the national curriculum with members of the public. For approximately an hour the debate ran smoothly, with questions and answers on various education-related topics, however the session then descended into abusive trolling, with the most offensive remarks being posted after the Prime Minister had logged off. By 'invading' what was intended as a civil and democratic dialogue on the Prime Minister's Facebook page, these trolls shifted the debate from public discourse to a highly personal attack. Unlike the trolls targeting Magda Szubanski on YouTube, these trolls were on a site hosted by and for communication with a specific person, albeit a public figure in her official capacity. The institutional context in which these speech acts were performed is public but directly targeted, thus sharpening their potential to enact not only illocutionary but perlocutionary force. Who is meant to be affected and acted upon is quite explicit. 
Julia Gillard, Australia's first female Prime Minister, was a divisive figure in Australian public life. Holding high public office makes very particular requirements of women in terms of persona management and gender identity. As Anne Cranny-Francis notes, "female politicians constantly deal with attacks that challenge their femininity rather than their policies and values" (26). What was publicly known of Gillard's private life presented a persona lacking in stereotypically feminine qualities - she was in a de facto relationship with a (male) hairdresser, childless, and apparently not skilled in the domestic arts (much was made of the empty fruit bowl photographed in her kitchen). In public life, she was a strong feminist politician, heading up a minority government where she was required to negotiate the balance of power with various independents. She was an object of hatred and vilification by right-wing groups, as expressed in the infamous "Ditch the witch" and "Juliar" signs held by protesters at a March 2011 rally against her government's planned introduction of a carbon tax. Yet Gillard was also much admired, particularly by feminist groups, for her strong and explicit feminist principles. The very same day the trolling incident took place, Gillard made her famous 'misogynism' speech in the Australian parliament (October 8, 2012), in which she defended herself and attacked the Opposition Leader, Tony Abbott, for his gendered double standards ("Gillard labels Abbott a misogynist"). Subsequently anti-feminist discourse against her has lost considerable ground as a legitimate form of attack, most particularly in the light of the immense public support not only within Australia but worldwide, ironically garnered substantially via another social medium, YouTube, where her speech had 2,764,308 views by February 2016 (with 32,243 likes and 2,029 dislikes).

Gillard's public persona was, in October 2012, one that had already been the target of abuse and personal attacks. In the trolling of her Facebook forum on education, the context was specifically a dialogue with Gillard's public persona, however this didn't prevent the trolls from attempting to target her in quite personal ways. The grammatical form and types of speech act employed demonstrate an escalated kind of trolling in comparison to our first case study. In this instance, the trolling utterances included not only constative but performative utterances, using the second person ('you') and directly addressed to Julia Gillard. In what constitutes one of the milder insults, one poster stated "Hopefully when you say "I have to go now" its [sic] back to your home planet'. The attacks drew on anti-feminist and misogynist rhetoric, some of it amounting to nothing more than primitive name-calling, such as the drawn out hissing insult 'SSSSSSSLLLLLLLLLLLLLLLLUUUUUUUUUUUUUUTTTTTTTTTTTTTTT!!!!!!!!'). This utterance, while expressing a strong affect of sexual contempt, does not require any action from the Prime Minister.

Likewise, the trolls also asked rhetorical questions, which expect no response but have the illocutionary force of insults because of the implicatures they generate. Asking Julia Gillard 'How's your dad?' was deliberately cruel and deeply offensive given the wide public knowledge that the Prime Minister had recently lost her father - and that talkback host Alan Jones had made an after dinner speech castigating Julia Gillard by saying her father 'died of shame' at his daughter's lies. It fails the Gricean principle of relevance at a literal level (the question is quite unrelated to the stated topic of education), but has strong relevance and affective resonance in relation to these recent events, which would have been well-known to all accessing the Facebook site. Another poster asked 'Are your pubes as radiant, shiny and glorious as mine?' again, not a sincere request for information, but a boundary-violating and lubricious speech act, with the illocutionary force of an insult.

These statements and questions, while sexist, derogatory and insulting, have no particular perlocutionary force, although they do have strong affective potential, and contribute to the overheated environment of the Facebook page. Some trolls did address direct commands 
to Gillard, including telling her to 'Lube up', 'Get my dinner ready' and 'McPiss off' (Hall, Whyte). 'Lube up' and 'Get my dinner ready', using sexist discourse to put down the Prime Minister and attempt to assert the primacy of phallocentric power over political power.4

Here again the trolls are violating the Gricean principle of relevance, in order to generate the implicature that it is Gillard's gender which is of overriding relevance, not her political performance or her education policies. All of these commands, issued apparently by predominantly male trolls, assert the speaker's power over the addressee and their supposed right to tell this upstart woman what to do. But in reality Julia Gillard is never going to cook one troll's dinner for him, nor perform sexual acts for another; these utterances confuse the public persona with the private individual. The commands are ultimately hollow illocutionary acts with little perlocutionary force.

The trolls on Julia Gillard's Facebook page were enacting a specific form of antifeminism, and in the ensuing media coverage and online debates men, as well as women, joined in condemning the trolls, while others attacked Gillard for having a 'glass jaw' and suggested 'playing the victim is working wonders for her poll results' (comments posted to Crikey.com, Whyte).

The Gillard Facebook debate constitutes an example of partially successful trolling. While Facebook as a social media site enables dialogue directly with the site's 'owner' as well as hosting content, it was being used in this case for a managed debate which unfolded over a specific and limited time-frame as an event in a politician's public engagement schedule. The affordances of Facebook enabled comments to be archived and therefore on the record for intended target (Gillard) to read later but also allowed for the most offensive of these posts to be removed by her staff, meaning she may not have seen them. The trolls' attacks did succeed to some extent in derailing the Facebook Education debate, but the strong affects of contempt articulated by the trolls' speech acts did not appear to have a direct effect on their target, who was in any case constituted through a public performance in her persona as Prime Minister, separate from the private individual. Their ineffectiveness was compounded by the fact that most were made after she had logged off the site, perhaps an indication of the false bravado of many trolls, who use the online environment to act out aggressive behaviour they would never display face-to-face. As in the Magda Szubanski case, the trolls' offensive and sexist speech acts did not succeed in the perlocutionary act of creating a 'victim', but rather incited a number of positive responses and expressions of support.

\section{Case Study 3: CharlotTe Dawson On TwitTer}

On August 30, 2012, Charlotte Dawson was admitted to hospital, following an overdose of prescription medication. This desperate act was the culmination of weeks of online aggression on her Twitter account, during which her battles with depression were made clear. Even more pressing, in terms of her suicide attempt, were the several hours of severe abuse prior to the act, during which Dawson was repeatedly told to 'go hang yourself', 'kill yourself', 'put your head in the toaster'; described as a whore and as a 'sad, ugly moll'; and sent images of bloodied corpses in an effort to make her understand her persecutors meant business (Hornery and Hall, Baird, Tarasov). At last, Dawson gave in to the will of the mob, posting a picture of a hand holding pills and two messages: 'You win $\mathrm{x}$ ' and 'Hope this ends the misery.'

Dawson's final tweet on that day demonstrates the extraordinary impact anonymous malicious trolling can have. For, although the vicious attack began only after Dawson managed to name and shame one of her abusers, Tanya Heti, the rest of the trolls remain unaccounted for. Heti infuriated Dawson days before when she tweeted that she could understand why the 
husband of a follower of Dawson would have committed suicide (Baird). She also responded with the message: 'On behalf of New Zealand we would like you to please go hang yourself', after Dawson had described her native country as 'small, nasty and vindictive' (AAP, 'Posts put in perspective'). Dawson discovered the university Heti worked for, and had her suspended from employment. At this point, the real barrage of anonymous threats, insults and commands began.

Dawson is an interesting figure in any discussion of malicious trolling. No stranger to conflict herself, as the well-publicised 'mean' judge on Australia's Next Top Model, she insulted would-be models for a living. For some, her performance of this role was enough to deny her sympathy, or to at least temper it (Hornery). However, to engage in this form of debate is to misrecognise the fundamental differences between a public and a private persona. Dawson was a public figure, playing a part; she cannot be simply and unproblematically collapsed into a cardboard cut-out caricature of herself.

Many trolls argue that their online abuse is playful (Insight, Johnston). If we look at the structure of the utterances in Dawson's case, it becomes very hard to believe that these attacks could have been anything other than serious. The vast majority of the statements made to Dawson were clearly perlocutionary performative utterances; they were commands to take action. As the crescendo built, and the mantra 'hang yourself' was repeated, the commands gathered an urgency demanding immediate response. This command is hardly subtle, and requires no inference from the reader. It cannot be argued that this injunction is merely acting as an insult, desiring nothing more than that the reader leaves the writer alone. The addition of images of corpses, making visually evident the expected and required outcome, put paid to that. Dawson is told what to do, and preferably, how to do it. There is no flouting of the conversational principle here; the message is self-evident.

Other speech acts directed at Dawson are more problematic. Dawson was told to 'put your head in the toaster', and described as 'fat', 'ugly' and a 'sad moll'. The first command demands an impossible act that, were it indeed possible, would destroy Dawson's face. Because it is literally impossible to carry out, it therefore generates an implicature. Flouting the conversational principle of clear, unambiguous speech, this strange command demands inference on the part of the reader that Dawson should not only die but be disfigured in her death. There is clear reference here to her career as a judge on a show evaluating the performance of models. The constatives on Dawson's appearance disparage her looks and thus challenge her right to speak at all regarding the looks and the style of others. The private individual Charlotte Dawson has clearly been confused and conflated with her job here; her public persona becomes her only persona and her performance of the performative 'mean judge' is equated with her personality.

This kind of attack, especially on women, is hardly new. Dawson herself had been the target of such vitriol many times before. On this occasion, however, she allowed it to affect her to such a degree that she took her pain out on her own body. Suddenly, the rude constatives and the appallingly violent performatives produced affect in the off-line world. In discussing why this should be the case, it is necessary to consider the discursive context of the statements, and the medium in which they were made, to determine why they had such affective intensity.

Dawson was a self-proclaimed avid Twitter devotee: "I like Twitter. I like the sense of community it creates, the ideas it gives us access to, its ability to make people feel closer intellectually and personally than they might otherwise be geographically or demographically." (Byrnes). Even after her attack, she had no intention of stopping her use of the medium and indeed did not until her suicide in February 2014. 
This statement, and her devotion to Twitter, lead us some way to discovering the reasons for her response to her abusers. Twitter is a conversational medium; fast moving, information can be shared back and forth with the speed of an off-line conversation. It doesn't have all the baggage of Facebook, which asks for an enormous amount of information on its users, and encourages them to keep up their profile by adding posts and attachments that are kept in a relatively static environment, so that it is easy to follow a thread from weeks prior. Twitter, on the other hand, is all about the present, demanding its followers keep up with current developments at all times, insisting on responses constantly. Twitter is designed to be a relatively simple form of social media, allowing its participants the feeling of being in the same time as those they follow, regardless of their geographical distance. It is the very nature of the medium, and the spare nature of the conversation it encourages, which creates its extraordinary affective intensity. No-one in the off-line world would ever have conversations such as those held on Twitter, where simple declarations or commands take the place of extended discourse. On Twitter, phatic communication is cut to a minimum, resulting in a world where social cues are frequently lost.

On August 30, 2012, Charlotte Dawson received a string of these simply worded messages, exhorting her to commit suicide in no uncertain terms. The phrase 'hang yourself' was repeated so often it became an act in and of itself: to write 'hang yourself' was to commit an act, to 'hang' Dawson both metaphorically in stopping her voice for a time, and literally in its clear demand which was ultimately followed through, although not to the letter. The closeness of the Twitter world was shattered for Dawson by those words. The community she had enjoyed engaging with turned against her, the intimacy she had experienced evaporated. The discursive context of Twitter, then, with its swift, unambiguous messages created such intensity of affect in Dawson that she overdosed. Yet, even in extremis, she reached out, yet again, with her tiny suicide note: 'You win $x x^{\prime}$.

\section{CONCLUSION}

In the three cases examined in this paper, the trolls conformed to certain stereotypical behaviour. Firstly, they chose to pick on a woman and a celebrity; two of the prime sufferers of vitriolic abuse online, according to Jason Wilson (cited in Hornery and Hall). Secondly, most of them prized their assumed anonymity, believing that this privilege guaranteed them free reign to say whatever they pleased. For, under the blanket of anonymity, trolls are able to ignore social constraints and write things they would never normally be able to say in the off-line world (Johnston).

While the cases share some similarities, we have demonstrated that the effectiveness of trolling differs with respect to the performative and affective nature of the utterances in each case. Using our three case studies, we have demonstrated a continuum of speech acts, from the constative and primarily illocutionary, to the performative and perlocutionary. In doing so, we have shown how the impact of the perlocutionary, combined with specific discursive contexts, can lend the utterance greater and greater power.

In the Szubanski case, the trolling took place on YouTube in response to a clip put up by producers of The Project. The trolls did make rude comments about Szubanski, but they were merely descriptive and generic. There is also no evidence that Szubanski even saw these comments as she did not maintain the site. Here we have an example of highly ineffective trolling. The utterances are generally constative, and thus have only illocutionary force. There is no demand for Szubanski to act in a particular way. The trolling of Julia Gillard's education forum on her Facebook site is only partially effective. The trolling took place after she had 
logged off, so was never seen by her in real time. Consisting of mostly garden-variety, constative insults and illocutionary rhetorical questions and commands, the comments lacked any relevance to the topic of conversation, and thus took on no more significance than the posturing adopted by playground bullies.

Nevertheless, action was taken: the posts were removed, and the Prime Minister began targeting trolls in an attempt to work out ways to catch them (Matheson). Yet, as with Szubanski, Gillard herself did not appear outwardly perturbed by the ludicrous comments aimed at her public persona. This is due to the relative lack of intimacy possible on a Facebook page dedicated to politics, and to the inescapable fact that she elicited such messages because of her high status and public role, which undercuts the effectiveness of the trolls' attempts to humiliate her. In the Charlotte Dawson incident, we see perlocutionary demands made repetitively and at fever pitch, insisting on a response. The discursive context of Twitter, perhaps the most intimate of the social media, contributed to increase the effectiveness of the statements and commands. Dawson maintained her own page and she saw every post as it came through, in real time. Eventually, the trolls succeeded, and Dawson attempted suicide in the offline world.

It is evident, then, that discursive context is essential in determining affective intensity and perlocutionary consequences: the more intimate a medium, the more results trolls can expect from malicious messages. The form of the medium is important as well; slower moving social media sites, such as YouTube and Facebook, are often read asynchronously which, in these instances at least, tended to distract from their power. Twitter, on the other hand, with its extraordinarily swift turnaround, demands constant attention, and thus an online campaign can be devastatingly destructive. The affordances of social media also enable greater or lesser degrees of separation between a public figure and their audience; from a more public and managed persona to a relatively intimate and private 'self'. Finally, the structure of the utterance differs on each medium, from the relatively lengthy messages possible on YouTube and Facebook, to the short, sharp commands and comments available on Twitter. The sense of intimacy on Twitter is also problematic for those subjected to trolling, as it encourages a sense of community through its real-time messaging which is as close to face-time as it is possible to get. The loss of this community can have dire consequences, as Dawson observed after her 2012 suicide attempt.

To conclude, malicious trolling is both possible and effective on all three of the social media platforms we looked at in this paper. However, the posts which have the greatest effectiveness, and especially those that create trouble in the off-line world, combine intensely personal and specific insults and commands with a page on a site that the victim considers particular to them, and which is experienced by the victim in real time. The more communal a page becomes, the less likely that trolling will be effective in a personal sense to an individual victim. The more perlocutionary and performative an utterance is, the more likely it will create long-lasting effects on its target. In the final degree, as we have demonstrated in this paper, malicious trolling can potentially lead to the death of the victim. Never have mere words been more powerful than in the virtual societies we now inhabit.

\section{END NOTES}

${ }^{1}$ Australia's first conviction for internet trolling was in 2011, and involved the defacing of Facebook tribute pages with child pornography (Keim). The Australian Criminal Code Part 
10.6 covers offences committed using the internet, including using a carriage service to menace, harass or cause offence (The Findlaw Team).

2 In 2015, Lena Durham, creator and writer of the HBO series Girls, chose to delegate the management of her Twitter account because of abusive tweets directed at her (Milsom).

3 Grice entitled his original paper "Logic and conversation", however his arguments apply to all dialogic communication, whether synchronous or asynchronous, as it accounts for the inferences made by the addressee or audience (in the case of YouTube and Facebook this includes those reading posts "after the event").

${ }^{4}$ The futility of this gesture was duly noted and commented on by others: "selfemasculating morons looking for a group hug" and "Some of you blokes need to have your right to vote revoked", comments posted on Crikey.com (see Whyte).

\section{WORKS CITED}

AAP. "Posts put in perspective." Newcastle Herald 31 Aug. 2012: 3. Print.

Atkinson, Paul \& Yell, Susan. "Affect, time and the enunciative body." Southern Review 38.2 (2006): 40-57. Print.

Austin J. L. How To Do Things With Words. Ed. J. O. Urmson. Oxford: Clarendon, 1962. Print.

Baird, Julia. "Inhuman, abusive trolls deserve exposure." Sydney Morning Herald 1 Sept. 2012. Web. 8 Feb. 2016.

Butler, Judith. Bodies That Matter. New York: Routledge, 1993. Print.

Byrnes, Holly. "Charlotte Dawson won't be silenced by Twitter trolls." The Daily Telegraph [Melbourne] 11 Sept. 2012. Web. 8 Feb. 2016.

Cranny-Francis, Anne. The Body in the Text. Carlton South: Melbourne University Press, 1995. Print.

Dahlberg, Lincoln. "Computer-mediated communications and the public sphere: A critical analysis." Journal of Computer-Mediated Communication 7.1 (2001):1-26. Web. 5 Feb. 2016.

Donath, Judith S. "Identity and deception in the virtual community." Communities in Cyberspace. Ed. Marc A. Smith and Peter Kollock. London: Routledge, 1999. 29-59. Print.

"Gillard labels Abbott a misogynist." ABC News (Australia). 8 Oct. 2012. Web. 9 Feb. 2016.

Grice, Elizabeth. "The sad, secret viciousness of the village troll." Sunday Age [Melbourne] 12 Oct. 2014, Extra: 22. Print.

Grice, H. Paul. "Logic and conversation." Syntax and Semantics. Ed. P. Cole and J.L. Morgan. New York: Academic Press, 1975. 41-58. Print.

Hall, Bianca. "A first for the PM but abusers take advantage." Sydney Morning Herald 9 Oct. 2012. Web. 5 Feb. 2016.

Halliday, M.A.K. Introduction to Functional Grammar. London: Edward Arnold, 1985. Print.

Hardaker, Claire. "Trolling in asynchronous computer-mediated communication: From user discussions to academic definitions." Journal of Politeness Research 6.2 (2010): 25-242. Print.

Herring, Susan, Kirk Job-Sluder, Rebecca Scheckler, \& Sasha Barab. "Searching for safety online: Managing "trolling" in a feminist forum." The Information Society: An International Journal 18.5 (2002): 371-384. Print.

Hornery, Andrew. "Dawson fights demons, trolls." Sydney Morning Herald 1 Sept. 2012. Web. 8 Feb. 2016. 
Hornery, Andrew and Bianca Hall. "Twitter torment: TV personality taken to hospital after abusive online attacks." Sydney Morning Herald 31 Aug. 2012. Web. 8 Feb. 2016.

Huffaker, David A. \& Sandra L. Calvert. "Gender, identity, and language use in teenage blogs." Journal of Computer-Mediated Communication 10.2 (2005): np. Web. 5 Feb. 2016.

Johnston, Megan. "The devil inside." Sydney Morning Herald 22 Sept. 2012. Web. 8 Feb. 2016.

Julia Gillard - Politician. Facebook. 9 Oct. 2012. Web. 16 Jan. 2013.

Keim, Tony. "Internet 'troll' Bradley Paul Hampson refused bail pending his appeal." Courier Mail [Brisbane]. 3 May 2011. Web. 4 Feb. 2016.

"Magda Szubanski on Gay Marriage - The Project." 14 Feb 2012. Online video clip and associated posts. YouTube. Web. 10 Dec. 2012.

Marshall, P. David and Kim Barbour. "Making intellectual room for Persona Studies: A new consciousness and a shifted perspective." Persona Studies 1.1 (2015): 1-12. Web. 20 Apr. 2016.

Marwick, Alice E. and danah boyd. "I tweet honestly, I tweet passionately: Twitter users, context collapse and the imagined audience." New Media Society 13 (2011): 114-133. Web. 20 Apr. 2016.

Massumi, Brian. “The Autonomy of Affect.” Deleuze: A Critical Reader. Ed. Paul Patton. Oxford: Blackwell, 1996: 217-239. Print.

Massumi, Brian. Parables for the Virtual: Movement, Affect, Sensation. Durham: Duke University Press, 2002. Print.

Matheson, Melissa. "Julia Gillard closing cyber troll net." The Daily Telegraph [Sydney], 17 Jan. 2013. Web. 8 Feb. 2016.

Narraine, Ryan. "The 10 biggest web annoyances." PC World (Dec. 2007):141-148. Print.

Paolillo, John C. "Structure and network in the YouTube core." Proceedings of the $21^{\text {st }}$ Hawaii International Conference on Systems Sciences. 7-10 Jan. 2008: 156. Web. 21 Apr. 2016

Quinn, Carl. "Gay-gay-gay-gay - Magda comes out" Sydney Morning Herald 15 Feb. 2012. Web. 4 Feb. 2016.

Rafferty, Rebecca S. "Motivations behind cyber bullying and online aggression: Cyber sanctions, dominance, and trolling online." Master of Arts thesis, College of Arts and Sciences, Ohio University, 2011. Web. 5 Feb. 2016.

Starke, Petra. "Julia Gillard the target of abuse on Facebook after trolls hijack live chat." Herald Sun, 9 Oct. 2012. Web. 14 Jan. 2013.

Tarasov, Anne. "Dawson: I will recover." Sydney Morning Herald 2 Sept. 2012. Web. 8 Feb. 2016. The Findlaw Team. "Internet Trolls can be prosecuted under Australian law." Thomson Reuters (Professional) Australia. 2016. Web. 5 Feb. 2016.

“Trolls." Insight. SBS. Host Jenny Brockie. 16 Oct. 2012. Television broadcast.

Turner, Tammara Combs, Marc A. Smith, Danyel Fisher and Howard T. Welser. "Picturing Usenet: Mapping computer-mediated collective action." Journal of Computer-Mediated Communication 10.4 (2005): np. Web. 5 Feb. 2016.

Van Zoonen, Liesbet. Feminist Media Studies. London: Sage, 1994. Print.

Whyte, Sally. "Gillard cops sexist spray in Facebook live chat." Crikey 8 Oct. 2012. Web. 12 Jan. 2013. 